\title{
Novela e imaginario étnico y nacional: una aproximación desde la literatura serbia ${ }^{1}$
}

\author{
JOAN FRIGOLÉ \\ Dpto. de Antropología Social \\ Universidad de Barcelona
}

\section{RESUMEN}

La hipótesis que guía el análisis de la novela El cucbillo, de Vuk Draskovitch, establece una relación entre las concepciones de procreación, parentesco, identidad nacional y genocidio. Los símbolos de procreación y las relaciones de parentesco constituyen el entramado simbólico de la identidad étnica y nacional. La obra analizada presenta el enfrentamiento entre identidades étnicas y nacionales determinado por un conflicto político y bélico que propicia el genocidio. Mientras en la novela la idea de Serbia se construye imaginariamente a través de las historias familiares de dos personajes y de referencias a un pasado lejano, en la realidad política la idea de Serbia se construía por oposición con los musulmanes de Kosovo, la región autónoma de Serbia. Se trata de una visión nacionalista del pasado, que destaca el protagonismo y el sufrimiento del pueblo serbio. Esta construcción de la "memoria" hubiera sido considerada antes de la muerte de Tito como instigación del chovinismo y probablemente del revanchismo, pero después, es un factor más en la redefinición de las identidades.

Palabras clave: Etnoliteratura, Identidad, Genocidio, Serbia, Vuk Draskovitch.

\section{SUMMARY}

The leading hypothesis for the analysis of the novel The Knife, by Vuk Draskovitch, establishes links among the concepts of procreation, kinship, national identity and genocide. Symbols of procreation and of kinship make up a framework for the notions of ethnic and national identity. The novel illustrates the struggle between ethnic and national identities which, driven by political and armed conflicts, nurture genocide. While in fiction the idea of Serbia is built upon the family history of two characters as well as references to a remote past, in real fact the idea of Serbia as a political entity was constructed in opposition to the Muslim community of Kosovo, the autonomous region of Serbia. This nationalistic vision of the past highlights the victimization and suffering of the Serbian people. Before Tito's death, such construction of "memory" would have

\footnotetext{
${ }^{1}$ Este texto fue escrito para el III Seminario de Etnoliteratura organizado por Manuel de la Fuente en la Universidad de Córdoba en 2001. Sin la entrañable personalidad de Manuel este texto no habría existido. Está dedicado a su memoria.
}

RDTP, LX, 1 (2005): 165-190 
been deemed an instigation to chauvinism and probably an instance of revenge, but in the end turns out to be just another factor in redefining identity.

Key words: Ethnoliterature, Identity, Genocide, Serbia, Vuk Draskovitch.

La novela El cuchillo de Vuk Draskovitch, publicada originalmente en 1982, narra la historia de un recién nacido que es robado, el cambio de su identidad familiar y étnico-religiosa, el descubrimiento posterior de su origen y el replanteamiento de su identidad. El niño pertenecía a la familia Jugovic, exterminada por los miembros de la familia Osmanovic ${ }^{2}$, con los que tenían relaciones de parentesco, compadrazgo y vecindad. Los hechos narrados se sitúan en Hercegovina, después de la invasión nazi de Yugoslavia en la segunda guerra mundial. Los verdugos son asociados con el régimen nazi implantado en Croacia, mientras que las víctimas son serbios. El protagonista es educado como musulmán. Sikter Efendija, un muecín, que reivindica simultáneamente la identidad musulmana y la ascendencia serbia, y por ello tiene una identidad marginal, desempeña un papel fundamental en el descubrimiento de la identidad del protagonista y en la solución a la misma.

¿Cómo leer una novela que relata el exterminio de una familia extensa serbia por parte de una musulmana como metáfora del genocidio serbio en 1942 en el contexto posterior al genocidio de los musulmanes de Bosnia, llevado a cabo por serbios y croatas en la década de los noventa? ¿Cómo leerla, siendo además el autor serbio? ¿Es la novela la continuidad de la confrontación política y étnica por otros medios? ¿Puede considerarse como parte de una campaña de inducción de los hechos posteriores? ¿Es una metáfora para la integración o para el odio?

La posición de la novela entre dos genocidios y sus relaciones mutuas condiciona mucho la perspectiva sobre la misma.

La novela $E l$ Cuchillo constituye una metáfora de un genocidio, un genocidio que es objeto de ficción, pero que se refiere a uno que realmente tuvo lugar. Una clave para la lectura de la obra puede ser la política de la memoria del pasado. La obra fue publicada poco después de la muerte del fundador de la República Socialista Federal de Yugoslavia, cuyo

2 El nombre del clan "se forma mediante el sufijo ic, ovic, o evic" (Halpern 1958: 12). Jugovic y Jugovici pueden evocar una figura de la épica popular serbia, "la madre de los nueve hijos Jugovicin (Hammel 1968: 25-26). Osmanovic está asociado con Osmanalilik (otomanismo) y Osmanlica (lengua otomana) e indica origen otomano. La contextualización etnográfica, un apoyo para la interpretación antropológica, aparece en forma de notas. 
lema era la unidad y la fraternidad entre los pueblos que la formaban. La mención a través de la ficción de un genocidio histórico, de sus víctimas y de sus perpetradores, desafiaba la política de la memoria del pasado, impuesta por el sistema político. El autor y la novela incurrían plenamente en el chovinismo, algo denostado y perseguido. A través de la ficción, un sector reprimido del pasado y una determinada imagen de él entraba a formar parte de la imaginación de la gente. La dimensión política de la novela radica no sólo en su contenido, en la imposición de unos determinados significados a unos símbolos, sino en el mismo hecho de evocar - a través de la ficción- unos hechos y hacerlo de una manera diferente $\mathrm{y}$, por tanto, contraria a la del sistema político. La memoria era un área sensible en términos políticos y el autor compitió con el estado por el control de la misma. El autor no sólo ficcionaliza un genocidio sino también un tema estrechamente relacionado con él, el de los orígenes y las identidades de las víctimas y de los perpetradores del crimen.

El segundo genocidio tuvo lugar en Bosnia a comienzos de la década de 1990, aproximadamente una década después de la publicación de la novela. Desde esta perspectiva, puede buscarse la clave de la lectura de la obra en el genocidio posterior y en la conexión con la ficcionalización de un genocidio anterior. Hasta qué punto la fabulación sobre el pasado ha contribuido al desencadenamiento de un nuevo genocidio. Ello plantea el tema de la responsabilidad del escritor y la repercusión social y política de la obra literaria. La etnóloga Nahoum-Grappe (1993: 66) ha relacionado esta novela con el genocidio de Bosnia, porque "alienta el odio contra los musulmanes", a pesar de que en la edición francesa (1993), que es la que he utilizado, se han eliminado las alusiones más odiosas contra los musulmanes. El historiador Sells (2001: 200) ha formulado posteriormente la misma crítica:

Los escritos del político Vuk Drakovi, en particular su No (El Cuchillo), han sido eficaces en incitar el odio contra todos los croatas y los musulmanes. Drakovi retrató a los musulmanes como serbios que traicionaron su raza al convertirse al Islam y, en el contexto de la segunda guerra mundial, como monstruos sádicos.

No pienso que pueda ofrecerse una respuesta simple o única a estas preguntas y problemas. Mi posición básica se concreta en la adopción de una perspectiva más bien interna a la novela y por ello creo prioritario considerarla como una totalidad y analizarla mediante un modelo antropológico, tal como he procedido en trabajos anteriores (Frigolé 1995, 1996 y 1997). 


\section{MODELO INTERPRETATIVO}

El modelo interpretativo está integrado por los conceptos de procreación, etnia/ nación y genocidio.

Procreación se refiere a las creencias y símbolos sobre el origen de la vida humana y al papel generador atribuido a ambos géneros. La concepción sobre la procreación constituye la base del parentesco y es fundamental para la definición de persona humana.

Etnia o grupo étnico es un concepto que uso en un sentido heurístico y por ello no ofrezco de entrada una definición sustantiva del mismo. Dos conceptos son indispensables para una definición específica de grupo étnico: oposición y contexto. La expresión de la identidad étnica es siempre relativa a oposiciones contextuales con otras identidades étnicas. La naturaleza de un grupo étnico es cultural, pero ello no resuelve de manera automática el problema de su definición. ¿Qué sucede cuando dos grupos étnicos comparten la misma lengua, territorio, cultura?

Lo más importante —en el sentido de lo más distintivo- en la definición de un grupo étnico no es tanto la cultura en su conjunto como la referencia a los orígenes, el relato o relatos sobre el origen o sobre el nacimiento del grupo y éste relato se expresa siempre en el lenguaje de la procreación y del parentesco, como dos aspectos de la misma realidad. Benedict (1993), al referirse a la nación y al nacionalismo, señala que para comprender su naturaleza hay que relacionarlos con categorías culturales básicas como parentesco y religión. Durkheim y Mauss (1996) establecieron que las clasificaciones primitivas del universo se estructuran sobre el modelo de los grupos sociales y sus relaciones; es decir, los hombres establecen semejanzas y diferencias entre los seres del universo según las semejanzas y las diferencias existentes entre ellos y éstas se expresan en términos de parentesco en los ejemplos elegidos por ambos autores. Falta sólo cerrar el círculo, señalando el papel de las concepciones sobre la procreación en la estructuración social y por tanto de las clasificaciones.

Siguiendo a Benedict (1993) y Bhaba (1990) caracterizo a la nación como un sistema cultural específico que hay que relacionar con otros sistemas similares. Los mitos genealógicos y las ficciones fundacionales basadas en el parentesco son elementos básicos del imaginario de las naciones.

Genocidio es el resultado de la acción planificada y sistemática de exterminio de un grupo definido o tratado como un grupo étnico por parte del poder político, del aparato de un Estado. La propagación de estereo- 
tipos totalmente negativos y estigmatizadores, que pretenden deshumanizar a los miembros de un determinado grupo, y por ello hacerlos vulnerables a todo tipo de agresiones, a la vez que las legitiman, juega un papel clave en la preparación del genocidio. El objetivo final de un genocidio es la eliminación real y simbólica de un grupo humano, incluida su "simiente", para que no pueda reproducirse. Por ello los niños son asesinados y/o robados por miembros del grupo que perpetra el genocidio. Se elimina su identidad originaria y se les asimila con el fin de que contribuyan a la reproducción del grupo agresor. Las mujeres son violadas y asesinadas. A veces las mujeres violadas son obligadas a parir los hijos, porque llevarán la identidad del grupo agresor. El ataque a la procreación es central en el genocidio. Puede verse un desarrollo de este mismo tema en trabajos míos anteriores (Frigolé 2003).

La hipótesis que guía el análisis de la obra establece una relación entre las concepciones de procreación, parentesco, identidad nacional y el genocidio. Los símbolos de procreación y las relaciones de parentesco constituyen el entramado simbólico de la identidad étnica y nacional. Este es el contexto de las representaciones colectivas, mientras que genocidio nos remite al contexto de las relaciones de poder. La obra analizada presenta el choque entre identidades étnicas y nacionales determinado por un conflicto político y bélico que propicia el genocidio.

ANÁLISIS DE LA OBRA

El inicio del primer capítulo tiene forma de dedicatoria:

Al viejo Vukasin, del pueblo de Klepac en Hercegovina.

Cuando en Jasenovac el degollador ustachi le cortó la oreja, Vukasin respondió con la serenidad de un santo: venga, hijo mío, haz tu tarea. Cuando el ustachi le cortó la otra oreja y la nariz y le sacó los ojos, escuchó las mismas palabras... (p. 9)

La dedicatoria representa la evocación del pasado y la memoria del pasado constituye el tema fundamental de la obra. El "martirio" de Vukasin es una alegoría que se proyecta sobre las muertes de víctimas indefensas, como los miembros de la familia Jugovic, torturados y asesinados por los Osmanovic, aliados de los ustachis. La evocación de Vukasin, situada inmediatamente debajo de "Navidad", título del capítulo, crea una disonancia. El tema del capítulo no va a ser la paz y el amor, connotaciones de Navidad, sino la guerra, el odio, el exterminio y el genocidio.

Los términos Jasenovac y ustachi evocan la historia política de Yugoslavia en el contexto de la segunda guerra mundial y de la invasión nazi. 
En el prefacio a la edición francesa, el autor describe Jasenovac como un campo de exterminio creado por los ustachis, cuarenta veces más grande que el campo alemán de Mauthausen. Ustachi designa a los partidarios del estado nazi creado en Croacia durante la segunda guerra mundial, que se independizó del estado yugoslavo. En la novela el conflicto principal es entre ustachis y no ustachis. Parte de los musulmanes son caracterizados como ustachis e incluso un personaje serbio los califica como "la flor y la nata" del ejército ustachi. La razón que se aduce para la alianza de los musulmanes con el estado ustachi de Croacia es que pretenden la independencia con respecto del estado yugoslavo, dominado por los serbios. Los serbios, presentados como los enemigos de los ustachis, se encuentran divididos en dos grupos enfrentados, los chetniks, partidarios de la monarquía, y los partisanos, comunistas. La identidad étnica común queda supeditada a lealtades políticas divididas y enfrentadas. El factor político es visto como determinante, pero mientras que en el conflicto entre ustachis y chetniks la dimensión étnica es muy importante, en el conflicto entre partisanos y ustachis no lo es. En la obra se habla de los crímenes de los ustachis, pero también se hace referencia a los crímenes de los chetniks, de tal manera que, como dice el muecín Sikter, no hay que diferenciar una matanza de los ustachis de otra de los chetniks. Se hace referencia también a los asesinatos o ejecuciones de los partisanos, pero, como dice una mujer musulmana: "por suerte no mataban a los niños y a las mujeres" (p. 109). Los partisanos no se hallan involucrados en un conflicto político que se represente como un conflicto étnico y por ello no persiguen la extinción de un grupo étnico. La contemporaneidad de la tortura y asesinato del viejo Vukasin en Jasenovac con los hechos que se narran a continuación acaecidos en Jugovici, un pueblo rural aislado de Hercegovina, en la Navidad de 1942, se indica por el mismo tipo de letra, en contraste con el pasado anterior que se representa mediante la cursiva. Se trata del asesinato de la totalidad de los miembros adultos de la familia Jugovic, formada por miembros de cuatro generaciones ${ }^{3}$, y del robo de un niño nacido la víspera de Navidad por parte de los Osmanovic. Los Jugovic son serbios ortodoxos (el mayor de los dos hermanos que preside la familia es el arcipreste Nicéforo), no están directamente implicados en el conflicto político y son más bien espectadores pasivos o dubitativos frente al mismo. Los Osmanovic son musulmanes y están involucrados activamente en el conflicto del lado de los ustachis.

${ }^{3}$ Se trata de la zadruga, un grupo familiar extenso característico de los eslavos del sur, formado por un hombre, su esposa y sus hijos casados con sus familias, y a veces los hermanos del hombre y sus familias" (Halpern 1958: 22). 
Los Jugovic y Osmanovic están relacionados por parentesco y compadrazgo $^{4}$.

La evocación de la tortura y degollación del viejo Vukasin por un ustachi innominado que precede a la descripción de la matanza de la familia Jugovic nos sitúa en un contexto que impide la percepción de ésta como fruto de un conflicto ancestral entre ambas familias. El exterminio de los Jugovic no tiene como detonante inicial la obligación familiar de vengar la sangre derramada, ya que no existe conflicto de sangre entre ellos 5 .

La matanza pone de manifiesto no la lógica de la venganza de sangre, sino la del genocidio. El término venganza tiene en la obra un significado ambivalente. Dada la estructura de parentesco de la trama, podría identificarse con venganza de sangre, pero el desplazamiento desde el plano familiar al plano étnico produce un cambio de sentido de la palabra venganza. Connota genocidio. Sirve para propagar la ideología del genocidio. La sangre derramada que reclama y legitima la venganza ya no es tanto familiar como étnica. Es preciso distinguir entre venganza de sangre y genocidio, pero el término venganza puede mezclarlas, al atribuir al genocidio características de la venganza de sangre.

Aunque el asesinato del viejo Vukasin constituye un indicio para el lector, la matanza colectiva de los Jugovic resulta imprevista, aterradora y gratuita. ¿Cómo se puede justificar? La escena ejemplifica la transformación radical, repentina y brutal de unas personas familiares y vecinas en seres despersonalizados, extraños, extranjeros, tal como pone de manifiesto la negación de los vínculos de parentesco, amistad y vecindad existentes $^{6}$, y la burla que los Osmanovic hacen de los rituales de reciprocidad y hospitalidad. Su ataque a los componentes básicos de la persona hu-

\footnotetext{
${ }^{4}$ Sobre las relaciones de compadrazgo Hammel (1968: 10) escribe: "Aunque los no cristianos son canónicamente inelegibles como padrinos y los musulmanes no tienen padrinazgo bautismal, los musulmanes actúan en algunas áreas como padrinos de bautizo para los cristianos (por lo menos en lo que a los campesinos se refiere) y los cristianos obtienen el título de kum (padrino) para los musulmanes participando en la circuncisión de sus niños".

${ }^{5}$ La venganza de sangre tiene como objetivo la muerte de un varón de un patrilinaje en compensación por la muerte de un varón de otro patrilinaje, dado que sólo éstos cuentan para la transmisión del linaje, y por ello las mujeres no son un objetivo de la venganza de sangre.

${ }^{6}$ A propósito de la guerra en Bosnia y Hercegovina de abril de 1992 y su impacto sobre los vecinos de una pequeña localidad, Bringa (1995: XVI) escribe: " Habiendo empezado como una guerra hecha por forasteros se convirtió en la guerra de vecino contra vecino, después que la figura familiar de éste hubiera sido substituida por la del forastero despersonalizado, miembro de las filas enemigasn.
} 
mana como el género, la generación, etc., se concreta en la violación de las mujeres delante de sus maridos y la muerte de los hijos delante de sus padres. La degollación por cuchillo, el tipo de muerte más frecuente, es la expresión más clara de la deshumanización a la que se les somete. El cuchillo es el instrumento mediante el cual se opera la deshumanización/ animalización de las víctimas. La mutilación previa a la degollación, como en el caso de Vukasin y de miembros de la familia Jugovic, es también una manera de significar el proceso de deshumanización. Se les convierte en seres monstruosos y por tanto se les excluye de la clasificación y de la condición de seres humanos. El uso del cuchillo no denota arcaísmo o algo parecido. No tiene sentido en este caso la contraposición entre arcaico y moderno. Los Osmanovic asaltan con armas automáticas la casa de los Jugovic, pero mutilan y matan a sus víctimas con el cuchillo?

¿Por qué ocurre algo tan brutal y horroroso de forma tan brusca? ¿Cómo puede suceder entre gente tan próxima? ¿Existe alguna explicación?

El origen de los Osmanovic es una rama de la línea genealógica de los Jugovic. La unidad y la homogeneidad inicial de los Jugovic, corporeizada y simbolizada por la genealogía, se escindió por la imposición del poder político, en este caso el imperio otomano, que eligió a un miembro de dicha familia para un cargo político y como consecuencia de ello se convirtió al Islam. La diferenciación religiosa-politica o, viceversa, determina la diferenciación familiar. Al mito de origen de los Jugovic - la unidad del grupo se basa en el parentesco que se pierde en el tiempo- se opone el relato de inicio de los Osmanovic, que se data, tanto en términos de profundidad genealógica como cronológica. Los Osmanovic llegan a percibir su origen como una carencia o inferioridad con respecto a los Jugovic. El parentesco es en este caso más un factor de división y discordia que de unión ${ }^{8}$.

\footnotetext{
${ }^{7}$ La siguiente referencia etnográfica clarifica la significación de la matanza: "El retóricamente fuerte término dabash (sacrificio), usado en la matanza de animales y el asesinato de hombres aparece frecuentemente en las narraciones de violencia. Su poder metafórico desplaza el acontecimiento al nivel sacro, diferenciándolo del cotidiano. [...] La metáfora 'sacrificio' santifica el acto de venganza y enfatiza su cualidad purificadora y meritoria así como su naturaleza obligatoria. El narrador hace el gesto de cortar el cuello de un animal, cruzando con fuerza el borde de su mano derecha sobre su muñeca izquierda como si fuera un cuchillo. El gesto se refiere a la forma islámica de sacrificar animales, que prescribe una fórmula verbal cuando se corta el cuello del animal. Otro efecto más del término dabash es el de animalizar la víctima de una manera muy específica y con un referente muy específico y presentarla como totalmente vulnerable al acto y al poder del sacrificador que la utiliza para su propia purificación" (Gilsenan 1996: 160).

${ }^{8}$ Casos parecidos a los de la novela han sido documentados. Bringa (1995: 18) habla de varios casos "de hermanos que han pertenecido a comunidades religiosas
} 
El asesinato de los Jugovic y el robo del recién nacido transforma la diferenciación inicial en ruptura definitiva. El exterminio del otro grupo supone la negación absoluta de la posibilidad de rehacer la unidad inicial y asegura un punto de partida único e independiente para los Osmanovic. Al niño se le impone el nombre de Alija, que es el que llevaba el antepasado fundador de la rama de los Osmanovic, que al convertirse al Islam cambió el nombre de Ilija por el de Alija. Los nombres son en este contexto indicadores no sólo de la identidad familiar, sino también de la identidad etno-religiosa ${ }^{9}$. Se podría presentar por lo menos en parte esta agresión entre semejantes y próximos como una agresión por el control del origen.

Nicéforo, que preside la familia Jugovic, defiende la validez de lazos de parentesco y de vecindad con los Osmanovic frente a Mitar, un jefe chetnik, que le previene y le urge a huir de su pueblo y refugiarse en los montes para evitar el ataque inminente de los Osmanovic. Nicéforo piensa que la huida sería considerada una ofensa por éstos. Nicéforo y Mitar expresan visiones contrapuestas sobre los Osmanovic. Mitar, consciente de la debilidad de los chetniks por falta de aliados exteriores, aconseja a Nicéforo que mande a sus sobrinos a luchar con los partisanos, porque son los únicos que pueden vencer a los Osmanovic:

Todo terminará por arreglarse, pero el odio de los Osmanovic no se extinguirá nunca. Recuérdalo, Nicéforo (p. 30).

Para Mitar los Osmanovic representan al enemigo étnico y político; Nicéforo los contempla fundamentalmente como parientes:

Somos primos, estamos unidos por lazos de sangre. No lo olvides. Perpetuamos estos lazos de sangre desde hace doscientos años (p. 30).

Mitar justifica su desconfianza precisamente en un relato sobre los orígenes de los Osmanovic, es decir, apela también al parentesco común, pero esta semejanza y proximidad son para él la explicación del odio de los Osmanovic:

diferentes a lo largo de la historia de la presencia otomana en Bosnia (y hasta avanzado el siglo diecinueve). Un hermano podía ser un cristiano ortodoxo, mientras que el otro declaraba su lealtad al Islam. Eliot (1908: 344) afirma que a veces una familia se dividía entre la Cristiandad y el Islam para tener amigos en el lado apropiado, pasara lo que pasara. En tales casos los miembros de la familia se reconocían mutuamente como parientes, pero generalmente usaban nombres diferentes que tenían el mismo significado en la lengua eslava y turca respectivamente».

9 «Los nombre propios indican también adscripción etno-religiosa. Los nombres propios de los musulmanes son de origen turco o árabe (islámico). (Bringa 1995: 19). Ver también la nota 16. 
Estos orígenes comunes son un ultraje a su conciencia y a su nombre (p. 31).

Mitar presenta el origen de los Osmanovic como una traición a la etnia serbia y a la religión ortodoxa, mientras que para Nicéforo se trata de una cuestión de fuerza mayor:

Era necesario convertirse o morir (p. 31).

Nicéforo ve a los Osmanovic como individuos, mientras que Mitar los contempla como grupo étnico aliado de los ustachis, enemigos de Yugoslavia, la "casa común". Mitar se muestra pesimista:

Cuando la estructura de la casa está podrida es inútil pintarla o tapar las grietas (p. 21).

Nicéforo le replica: "Nuestra casa era nueva" (p. 21), en alusión a la corta existencia del estado yugoslavo.

No es la diferenciación pasada, ni las susceptibilidades que ella pueda suscitar, lo que explica la acción de los Osmanovic, sino la polarización política y la intensificación de la guerra lo que hace que los vínculos de parentesco se vuelvan débiles e ineficaces. La ruptura es mucho más dura porque el contexto es mucho más duro, extremo. El parentesco no resiste el odio político y étnico potenciado por la guerra. La polarización política impone exclusividad en las lealtades, lo que acabará deteriorando las relaciones entre los Osmanovic y los Jugovic.

La celebración de la Navidad ortodoxa adquiere connotaciones muy especiales para los Jugovic por el nacimiento, en la víspera, del primogénito de la cuarta generación. Un primogénito que representa la garantía de la continuidad del linaje. Y éste es precisamente el niño que será robado por los Osmanovic. La Navidad se caracteriza por rituales de reciprocidad para con los familiares y vecinos y, en especial, con los primeros vecinos que entran en la casa ese día. Es también el momento adecuado para interrogar el futuro próximo. Nicéforo, el hombre de mayor rango jerárquico, inicia la ronda de adivinación, consistente en ver si se refleja su rostro en la grasa de la polenta de la olla común en el centro de la mesa, preparada para la comida familiar. El reflejo o su ausencia se interpretan como la continuidad de la vida o la muerte en el año entrante. En este momento, los Osmanovic hacen su entrada en la casa. Se trata de un asalto, ya que penetran rompiendo los cristales de la ventana y la cerradura de la puerta y les encañonan. Los Jugovic los tratan como los primeros vecinos que visitan su casa el día de Navidad, con los que se tienen obligaciones rituales específicas, básicamente el regalo de piezas de ropa, camisas y calcetines en este caso, un regalo tradicional que 
se hace también a los invitados a una boda. Los primeros vecinos del día de Navidad son también indicadores de suerte o desgracia para la casa durante el próximo año ${ }^{10}$. Los Jugovic les tratan como parientes, pero los Osmanovic lo rechazan:

¿Por qué me recuerdas sin parar que somos primos, por qué me ofreces de beber como si me invitaras a una boda? (p. 36).

Los vínculos de parentesco y de vecindad se han roto y la entrada de los Osmanovic sólo anuncia desgracia y muerte.

En este contexto, todas las referencias a la procreación no son accesorias, sino fundamentales, dado que anuncian la agresión y matanza posteriores y el fin y significado último de las mismas. La maldición inicial de Husein a los Jugovic anuncia el genocidio posterior:

Que Alá haga morir a todos los hijos en sus entrañas (p. 35).

Zulfikar esparce trigo en la casa "como si sembrara en medio de su campo" (p. 35), un gesto significativo que anuncia la violación de las mujeres, consideradas "campos" humanos. Un muecín, que forma parte de los Osmanovic, decide el destino del niño con estas palabras:

Que el linaje de Alija nazca una vez más de la sangre y la simiente de los Jugovic (p. 63).

La simiente es una metáfora sobre la procreación. Nicéforo maldice con la misma metáfora:

Que tu simiente se vuelva veneno (p. 59),

cuando contempla impotente el exterminio de los suyos. Su único recurso simbólico es la maldición de aquello que representa el poder generativo y la continuidad de la vida para los otros. No puede escapar a la lógica que impone el genocidio. Las metáforas de procreación se transforman en metáforas de destrucción.

Nicéforo, al darse cuenta del destino que quieren dar al niño, el único superviviente que podría garantizar a pesar de todo la continuidad de su linaje, grita una palabra que antes había evitado:

${ }^{10}$ Halpern (1958: 244) escribe: "Se cree que un visitante indeseable la mañana de Navidad puede traer mala suerte a la casa. Ello se contrarresta haciendo que alguno de la casa, habitualmente un chico, salga y golpee a la puerta pidiendo entrar. De esta manera la familia siempre puede estar segura del carácter del polazenik o primer huésped. Él entra gritando 'Cristo ha nacido' y es recibido cálidamente. La esposa del cabeza de familia le lanza un puñado de grano". 
Una terrible maldición se abatió sobre el traidor. Y de pena mortal, la madre maldijo al hijo (p. 61).

Parece un fragmento de un poema, que evoca un hecho histórico, símbolo de la ruptura de lealtades entre "hermanos". La madre patria maldijo al hijo traidor. A través de la evocación de Nicéforo, la madre patria maldice de nuevo al hijo traidor. Nicéforo sitúa la traición de los Osmanovic a la lealtad familiar en el contexto de la traición a la patria. Los Osmanovic serían doblemente traidores. La ruptura es total.

Los Osmanovic eliminan no sólo la rama de los Jugovic, sino que destruyen también sus casas y la iglesia, hecha construir por el antepasado convertido al Islam para sus padres. La destrucción de casas y monumentos es la otra cara del genocidio. La matanza se extiende a todo el pueblo de Jugovici. Nicéforo y los restantes vecinos son encerrados y quemados en la iglesia.

Alija es criado y educado como un Osmanovic y por tanto como musulmán. Pero la apropiación simbólica por parte de los Osmanovic tiene un límite impuesto por la religión musulmana, que prohibe la confusión con respecto a la filiación. Se le dirá que es huérfano de padres, porque los chetniks los mataron. Los Osmanovic no sólo le cambian el origen familiar, sino también el lugar de procedencia, es decir, lo adscriben a una parte distinta del territorio de Hercegovina. Legalmente figura como hijo de padres desconocidos. El niño es amamantado por la mujer del primogénito de los Osmanovic, que está criando a su primer hijo ${ }^{11}$.

Los Osmanovic fueron atacados, primero por el jefe chetnik Mitar que quiere recuperar al niño robado y vengar la muerte de los Jugovic y después por los partisanos por ser ustachis. Morirá la mayoría de los varones Osmanovic. La madre adoptiva culpa a los serbios de todas las desgracias de la familia. Alija crecerá asumiendo esta visión. Su experiencia infantil como pastor y las peleas con niños pastores serbios de pueblos vecinos reforzarán los estereotipos negativos y el odio étnicos. Su trayectoria sufrirá un cambio cuando, como huérfano de guerra y alumno aplicado, acceda por decisión de las autoridades a los estudios secundarios y posteriormente a la Universidad. El desplazamiento a la ciudad de

${ }^{11}$ Bringa (1995: 146-47) escribe sobre el parentesco de leche: «Los musulmanes, no obstante, tienen una restricción adicional a la hora de elegir la persona con que casarse. El matrimonio con los que están relacionados 'a través de la leche' es un tabú tan serio como el que afecta al matrimonio con parientes. Esto significa que una persona que ha sido amamantada por una mujer diferente de su madre, no puede casarse con una persona que ha sido amamantada por la misma mujer. Las personas amamantadas por la misma mujer se llaman hermana o hermano 'de leche"”. 
Sarajevo en su etapa universitaria acentuará la relación y la convivencia multiétnica, lo que repercutirá en la relación con su madre. La tensión con su madre se acentuará a causa de una novia serbia. La oposición radical de la madre a ella no hará derivar la novela hacia un romance, que crea la unidad a partir de diferencias consideradas irreductibles ${ }^{12}$. Por el contrario, la lógica dominante está relacionada con la pérdida de la unidad original, causada por la ruptura de una genealogía común y sólo Alija puede simbolizar la recuperación de la unidad.

La evocación inicial del primer capítulo nos avanza el tema del segundo: la recuperación y la reivindicación de la memoria histórica de las matanzas. Veinte años después de la capitulación de Yugoslavia ante el invasor nazi en 1941, se procede a la exhumación de 37 serbios asesinados por los ustachis aquel mismo año y enterrados en una fosa común cerca de una iglesia, que fue también destruida. La iglesia ha sido reconstruida y repican de nuevo las campanas. Preside la ceremonia el obispo de Mostar desplazado para tal ocasión. Alija y Dragica, una muchacha serbia, son elegidos para iniciar simbólicamente la excavación de la fosa común. No se dice nada sobre la localización de la zona, pero no es Jugovici, destruido por los Osmanovic. La pareja formada por Alija y Dragica simboliza la superación del pasado. El obispo habla de la superación del pasado, pero insiste en la obligación de rebatir y reparar "las mentiras y el olvido con los que se intenta cubrir los osarios y las fosas comunes" (p. 67). El obispo finaliza con este deseo:

Que jamás vuelva el tiempo de los cuchillos, que fue el tiempo de nuestra destrucción (p. 68).

Todos los cadáveres exhumados muestran señales de cuchillos u otros objetos cortantes o punzantes o incluso los contienen. Las cabezas están separadas de los troncos. Se trata de una muerte totalmente manual, sin distancia, personalizada, frente a la muerte más mecánica, distanciada e impersonal por arma de fuego. El tipo de muerte indica también que se trata del sacrificio de víctimas indefensas. Los términos mártir y martirio son evocados. Cuando el obispo termina el recitado de los nombres de los degollados y la oración por ellos, un viejo se le acerca y le pide que

${ }^{12}$ Sommer (1990: 75) utiliza el término romance a propósito de novelas latinoamericanas del siglo XIX, que considera mitos fundacionales de naciones modernas, y lo define como un híbrido entre nuestro uso contemporáneo del término como historia de amor y el uso decimonónico que caracterizaba el romance como más marcadamente alegórico que la novela. Los romances latinoamericanos son inevitablemente historias de amantes de orígenes dispares que representan regiones, razas, partidos, o intereses económicos específicos que tendrían que unirse naturalmentem. 
recite un responso por las víctimas de todas las matanzas, entre otras la de los Jugovic, no importa "donde se pudran o estén enterradas" (p. 87). $\mathrm{Al}$ responderle que no conoce sus nombres, el viejo le dice que recite todos los nombres serbios que existen, ya que "han degollado todos los nombres serbios" (p. 87). El capítulo se cierra con la fórmula "memoria eterna" - título del capítulo- que los asistentes repiten tres veces después del recitado de los nombres serbios ${ }^{13}$. No hay referencia explícita a la presencia de la autoridad política. El acto es familiar, local, y sólo la petición del viejo lo convierte en el último instante en una conmemoración con implicaciones generales. Este dramático acto aviva en Alija el interés por el conocimiento de su origen y las circunstancias del asesinato de sus padres y familiares.

La obra se centra a partir de este momento en la trayectoria de Alija y en el personaje de Sikter Efendija, que prepara a Alija para la comprensión de su origen, de la historia de la familia, de las identidades y de los conflictos. Desde la exhumación de la fosa común las pesadillas turban el sueño de Alija. Éste no guarda memoria del exterminio de su familia ni de lo que él llama "locura fratricida", pero la imagen de cuchillos que amenazan con cortarle el cuello, se convierte en una pesadilla nocturna habitual. Sueña también con cabezas cortadas y con el asesinato de su familia. Alija habla de la obsesión de la gente por los cuchillos y de que ésta se vuelve loca con ellos en la mano. Milica, su novia serbia, le aconseja que visite Foca, donde le dijeron que fue hallado, y pregunte a la gente, para aclarar la incógnita de su origen y poner fin a sus pesadillas. Alija le responde que ya lo hizo y que ha leído también la literatura sobre la masacre de los musulmanes de Foca y Goradze por los chetniks, sin ningún resultado. A continuación, Milica le sugiere que dé publicidad a su caso a través de un anuncio en un periódico. La publicación de un anuncio, dado su esquematismo, podría ser considerado por las autoridades como un intento de reavivar el revanchismo. La solución adoptada será un reportaje centrado en él y, por tanto, particularizando el caso. El reportaje es leído por mucha gente y la noticia del mismo

${ }^{13}$ Halpern (1958: 14) escribe sobre la fiesta nacional serbia, Vidovdan, asociada con la conquista turca, "los nombres de todos aquellos que han muerto en las guerras de la nación son leídos en las iglesias". Según Sells (2001: 181), la fiesta conmemora la «muerte del príncipe serbio Lazar en 1389 por el ejército otomano [...] en la que Lazar es asociado con Cristo y el lugar de su muerte es llamado el 'Gólgota serbio'». Las diferencias en la descripción pueden deberse en parte a las distintas épocas a la que se refieren, la de Halpern, a la primera mitad de la década de los cincuenta, bajo el control de la República Yugoslava, y la de Sells, a finales de los noventa, en la que ya estaba desmembrada. 
llega también a su madre, que se muestra dolida e irritada por lo que la acción de Alija representa para ella. Alija recibe cartas de muchos lectores, una parte de las cuales traslucen odio político y étnico, a pesar del tiempo transcurrido desde los hechos narrados en el primer capítulo. Una carta tardía, remitida anónimamente desde Belgrado, resultará ser clave para aclarar su origen. La envió un zapatero llamado Muharem, casado con una Osmanovic, y residente en Sarajevo. Él se considera un vencido, y consciente de su débil posición y de las potenciales repercusiones conflictivas del caso, adopta una estrategia de precaución. La carta finaliza con esta paradoja:

Existe una sola certeza, no eres el que eres y eres el que no eres (p. 169)

Todo el texto es indescifrable para Alija.

Sikter Efendija es un personaje clave para la interpretación de esta carta y la evolución posterior de Alija. Sikter es un muecín, de sesenta años, soltero y solitario, despreciado - Sikter es un apodo sinónimo de loco, impuesto cuando negó su apoyo a la causa ustachi-, y considerado incluso un traidor por los musulmanes. Pero Sikter es también un personaje conocedor del pasado, reflexivo y profundamente religioso. Mantiene buenas relaciones con sus vecinos serbios. Sikter representa la unión de dos elementos opuestos, la religión musulmana y la identidad serbia. A él la religión no le impone la renuncia de su pasado ni la identificación con invasores y dominadores extranjeros. Él, que es profundamente musulmán, sabe que la identificación religiosa ha sido cambiante en el pasado y dependiente en gran parte de la estratificación social y de factores políticos, de manera semejante a como pensaba Nicéforo; es decir, una cuestión de supervivencia en ciertas épocas del pasado. La estrategia de Sikter consiste en relatar a Alija una serie de historias, que ponen de relieve la continuidad del vínculo genealógico entre diversas familias o ramas familiares, para que él comprenda que existe una identidad común basada en el reconocimiento de un vínculo genealógico a partir de un mismo origen. Las diferencias de religión o, de otro tipo, aunque significativas, han sido sobreañadidas y por ello son secundarias en relación a la continuidad genealógica. Sikter considera que la desgracia que afecta a su pueblo es el resultado de haber consagrado las diferencias sobreañadidas como más importantes que la continuidad de los lazos de parentesco y de haber creado una memoria fragmentada de la gran genealogía común, de no haber sabido, como supieron diversos antepasados, hacer compatibles la continuidad de los lazos genealógicos con las distancias creadas por factores exógenos. Para que Alija sea consciente de la profundidad de los lazos genealógicos, le pide que le recite la lista de antepasados a 
partir del cincuentavo. Alija lo considera imposible, ya que sólo ha aprendido a remontarse hasta su antepasado no muy remoto del que él lleva el nombre ${ }^{14}$. Sikter le replica:

¿Cómo Alija puede ser el último, cuando hace quince siglos que nacemos, nos casamos y morimos bajo estos cielos? [...] No tienes más que hacer la cuenta tu mismo; si se cuentan cuatro generaciones por siglo, hay por lo menos cincuenta o sesenta generaciones de antepasados que nos han precedido, a ti y a mí (p. 188).

Sikter expone a Alija una concepción unitaria de la identidad que integra tanto a sus antepasados musulmanes como no musulmanes.

Tal como me ves, yo soy una sola cosa, el descendiente de Safet-bey y el servidor de Alá, pero desciendo también de Djouro Barbaric. Si renegara de Djouro, renegaría al mismo tiempo de Safet-bey y la religión de Mahoma. Yo perdería mis raíces, no sería nadie, no sería nada, sería un eterno extranjero a donde fuera y fuese cual fuese mi nombre. Djouro es para mí un nexo tanto con el pasado como con el futuro. Y porque no he renegado de él, puedo remontarme hasta quince siglos atrás. No tengo necesidad de taparme con el velo del olvido para preservar mi consciencia (p. 189).

Esta cincuentena de antepasados, símbolo clave del parentesco y la procreación, son también en el contexto citado un símbolo potente de la identidad étnica ${ }^{15}$.

Sikter representa la unidad de los contrarios. La oposición entre serbios

${ }^{14}$ Hammel (1968: 26) señala que «el recuento genealógico en la mayor parte de Yugoslavia es primariamente agnático".

${ }^{15}$ Hammel (1968: 26), refiriéndose al conjunto de Yugoslavia, dice que sus informantes "pueden a menudo enumerar de diez a catorce generaciones de ascendientes directos", pero Bringa (1995: 31) señala para Bosnia que «los etnógrafos han observado que los musulmanes tienen poco conocimiento o interés en su genealogía en comparación con los serbios o los croatas". Bringa (1995:30) relaciona la falta de interés de los musulmanes por la genealogía como reacción a la posición de serbios y croatas respecto a su origen: “El único habitante serbio de Dolina, el pueblo en el que hice mi trabajo de campo, diría en broma a sus amigos musulmanes que tenían sangre serbia en sus venas". Otro ejemplo de la actitud de los serbios respecto al origen de los musulmanes: "El sacerdote católico de un pueblo vecino tenía el mismo apellido que una destacada familia musulmana del pueblo. El sacerdote afirmaba que el hermano de uno de sus antepasados se había convertido al Islam y que los musulmanes del pueblo con el mismo apellido eran los descendientes de aquel hombre. No obstante, los propios musulmanes no sabían si esto era cierto" (Bringa 1995: 23839). Por contraposición a la filiación común para representar la identidad colectiva, los musulmanes enfatizan eel medio compartido, las prácticas culturales, el sentimiento compartido y las experiencias comunes" (Bringa 1995: 30). En la novela quienes hablan de parentesco y de lazos genealógicos entre Jugovic y Osmanovic son los Jugovic, serbios, y Sikter Efendija, un musulmán atípico. 
y musulmanes es para él ilegítima y perjudicial, ya que está basada en una historia/memoria parcial y selectiva. Sikter intenta que Alija, al descubrir su origen, concilie las oposiciones existentes mediante el conocimiento y la asunción de una memoria histórica profunda. Sikter es un personaje utópico.

El descubrimiento de su origen sitúa al protagonista en una posición marginal. Ha dejado de ser lo que era, pero todavía no ha asumido lo que puede llegar a ser, Alija-Ilija, la figura inversa pero complementaria de la de su antepasado cuyo nombre era Ilija, un nombre serbio, que cambió por el de Alija tras su adhesión al Islam ${ }^{16}$.

Sikter recomienda a Alija que asuma las dos identidades a través de la aceptación de sus dos madres:

Tú no debes renunciar a lo que eras todavía ayer, pero tienes que acostumbrarte a los nuevos vestidos, incluso si te parecen todavía demasiado estrechos. [...] Yo llevo los vestidos de Safet-bey y de Djouro Barbaric. Llevo el zapato de Djouro en el pie izquierdo y, el de Safet en el derecho. Sólo los ignorantes pueden creer que mis zapatos no están aparejados. [...] Sigue con lo mismo, con los zapatos que llevabas hasta ahora. No hay que separar el zapato de Rabija del de Ljubica. Ljubica era tu madre, tú mismo lo has leído en este cuaderno. Una te trajo al mundo y la otra te ha alimentado y criado. La primera te dio la vida y la segunda te la ha conservado (p. 252).

La afirmación de la complementariedad de los dos antepasados queda matizada por la asimetría que introduce la oposición derecho/izquierdo. Más adelante Alija le explicará a Sikter que no puede llevar los zapatos, porque no forman un par y le hacen daño. Está decidido a borrar a los Osmanovic de su memoria. Sikter le razona en estos términos:

Incluso si lo quisieras, no podrías borrar jamás todos los años pasados que llevas contigo. Tú no puedes rechazar a los Osmanovic, no tienes el derecho a hacerlo, si quieres seguir la evolución a la que estás destinado y de la que yo no te desviaré. Sin pasado, el futuro sólo puede ser un lugar vacío. Tú no puedes renacer, si niegas tu primer nacimiento.

Alija le replica:

Todo esto es muy bonito y seguramente muy inteligente, pero yo no puedo vivir siendo a la vez un Osmanovic y un Jugovic, son dos identidades incompatibles. Todos los vínculos que antes les unían, han sido rotos (p. 286).

16 En Bosnia existe el siguiente refrán, "hasta el mediodía Ilija (Elijah), desde el mediodía Alijan. Este dicho se refiere a la celebración musulmana del Alidun y a la celebración serbia ortodoxa del Ilindan, que tienen lugar el día dos de agosto" (Bringa 1995:17). Es la festividad del profeta Elías, celebrada por la Iglesia ortodoxa y por el Islam popular. 
Sikter insiste en la existencia de un vínculo fuerte e indestructible entre los Osmanovic y los Jugovic, que Alija es incapaz de ver: "Y este vínculo eres tú" (p. 286).

La lógica de Sikter es genealógica: Alija no debe contraponer ambas sangres, porque él no es tanto miembro de una familia, opuesta a otra, como de un linaje mucho más grande, que las engloba, y del que él, como varón, es un eslabón necesario. El camino a seguir es inverso y complementario del de su antepasado Alija que se hizo musulmán, pero que mandó construir la iglesia de Jugovici para sus padres y, como indica este hecho, no rompió ni los lazos familiares ni genealógicos. Para Sikter recuperar el origen no implica cambio de linaje ya que para él la continuidad del linaje es el factor identitario principal. No obstante, la idea de venganza está presente en el camino doloroso y ambivalente de asunción de una nueva identidad que experimenta Alija, un proceso que consta de movimientos simultáneos de afirmación y de rechazo. El rechazo se plantea también como un ajuste de cuentas simbólico con su antigua familia. Pero su sed de venganza se irá deshinchando y se limitará a una posible denuncia de algunos miembros de su familia de adopción de los que sospecha pudieran haber estado involucrados en la matanza de su familia de origen. Las referencias al par de zapatos y posteriormente a las muletas constituyen metáforas básicas consistentes entre sí, que expresan los problemas que experimenta el protagonista: cómo hacer casar elementos considerados hasta el momento diferentes y contrarios entre sí, cómo apoyarse en ellos para crear un nuevo orden y una nueva identidad.

Sikter explora las consecuencias negativas de no reconocer la identidad de semejanzas a través de la parábola de los dos sauces. Un sauce pequeño que ha brotado del pie de uno más grande siente envidia y odio hacia éste y por ello desea que el leñador lo tale, lo cual comportaría también su propia desaparición.

La forja de la nueva identidad de Alija se basa no sólo en el descubrimiento de su origen familiar y en asumir este origen como punto de partida para su nueva identidad, sino también en el descubrimiento de la historia real de su país en la época en que él fue robado. Sikter le ha enviado un pliego de papeles, copias de cartas, informes, peticiones, textos, noticias de prensa, etc., redactados por diversos y variados protagonistas individuales o colectivos, en su mayoría testigos de los hechos que le afectan. Su lectura le hace descubrir la amplitud del genocidio serbio, el papel y la responsabilidad de los poderes que lo han instigado, de los ejecutores y de los encubridores, pero también actitudes firmes y valientes de denuncia por parte de no serbios. Mientras en los capítulos anteriores el pasado era representado por la memoria de los protagonistas, 
en el capítulo final, en que Alija se ha quedado sólo, el pasado es representado por "documentos históricos". Éstos proporcionan un contexto más amplio a los acontecimientos iniciales, que determinaron la trayectoria de Alija, y reafirman el carácter de conflicto político y de genocidio de los mismos. En el primer "documento" Alija lee entre otras muchas cosas:

El exterminio de los serbios empezó inmediatamente después de la declaración de independencia del funesto estado independiente de Croacia. En Gospic, Glina, Gudovac, Bosanska Krajina, y en tantos otros lugares, se prosigue hasta el día de hoy. El horror no está sólo en el hecho de que se masacra indiscriminadamente a viejos, mujeres y niños, sino en la crueldad, la horrenda barbarie de los suplicios a que se les somete (p. 308).

Sikter le había escrito al enviarle los textos:

Yo no he hecho más que entreabrir las puertas del infierno ante tus ojos. Pero el viejo Lazar te acompañará en este camino (p. 332).

Alija no sabe quién es Lazar, al que ha sido confiado y que espera su visita. Alija no recuerda que Sikter le había mencionado, al relatar la muerte cruel de la nuera de este hombre durante el genocidio. Alija debe conocer el pasado para forjarse una memoria histórica que no es la suya, pero que debe hacer suya. Este viaje al pasado se le presenta como un viaje al infierno del horror y se lamenta por ello:

Qué miserable vida. Lazar Vukotic sólo me presentará muertos. [...] iQué horror! ¿Qué es lo que un vivo puede decir a los muertos? Pero los muertos, todos los degollados, ¿tendrán algo que decir a los vivos? (p. 333).

Alija no puede eludir la visita a Lazar, que vive fuera de Sarajevo. Este viaje representará otra etapa en el viaje hacia el pasado que inició de la mano de Sikter. La nueva identidad, familiar, étnica y nacional de Alija se fundamentará en la construcción -invención se dice también en la obra-, de una nueva memoria histórica.

El libro finaliza con el sonido de las campanas de la catedral de Sarajevo:

Ellas tocaban lentamente, regularmente y Alija Osmanovic tenía la impresión de que estas notas formaban un único sonido, una sola palabra: ¡el cuchillo!, jel cuchillo! (p. 333)

El protagonista ha mantenido el nombre y el apellido musulmanes hasta el final de la obra, a pesar de haberse asegurado a sí mismo que no eran los suyos y de haber tenido la intención de cambiarlos, a lo que hay que sumar el rechazo simbólico hacia su madre adoptiva. La identificación del protagonista mediante su nombre y apellido iniciales puede 
interpretarse como que para ser Jugovic, y por extensión afirmar su identidad serbia, no necesita cambiar de nombre. La trayectoria de Alija puede ser considerada también una metáfora sobre los musulmanes: sois como Alija, es decir, igual que él, si recuperáis la memoria de vuestro origen, descubriréis que sois serbios, lo cual no debería comportar ninguna renuncia. La referencia al cuchillo introduce una discrepancia con esta lógica de la complementariedad que parece prevalecer. ¿Se trata de una evocación de sus antiguas pesadillas reavivadas como consecuencia del impacto de las revelaciones, de la sed de venganza que experimenta en algunos momentos, a pesar de que siente horror por los cuchillos, o de la premonición de un nuevo genocidio?

El mantenimiento del nombre apunta al parentesco, un factor fundamental para expresar la unidad de la identidad y la imagen del cuchillo, a la historia como generadora de división y diferenciación. La unidad y la continuidad del parentesco se oponen a los conflictos y rupturas de la historia. Sikter contraponía la genealogía a la historia y quería que la primera se impusiera a la segunda, pero la obra no cierra la posibilidad de que ésta fuera de nuevo dominante.

\section{CONTEXTUALIZACIÓN HISTÓRICA DE LA OBRA}

La contextualización histórica y literaria de la obra puede contribuir a aclarar el por qué o la significación de las decisiones básicas, implícitas o explícitas, tomadas por el autor durante el proceso de escritura. Algunas de las preguntas a considerar son: ¿Por qué eligió el escenario de Hercegovina y no otro? ¿Por qué situó el inicio de la trama en el marco de la invasión nazi de la segunda guerra mundial y no en otro momento histórico? ¿Por qué escogió unas categorías y unas oposiciones étnicas y no otras? ¿Por qué les atribuyó una significación y no otra? ¿Hasta qué punto el desarrollo de la trama sigue, o no, el modelo de obras anteriores?

La contextualización histórica tendría que dar respuesta a preguntas tales como ¿Cuáles eran los discursos sobre la identidad que dominaban en la época en que se escribió la obra? ¿Qué tipo de historia oficial se difundía y qué versiones eran marginadas? ¿Qué imágenes y símbolos del pasado se destacaban? ¿Qué temores relacionados con el pasado eran reavivados? ¿Qué ideales y alternativas se proponían y cuáles se rechazaban? ¿Qué premisas, imágenes, etc., comparte o rechaza el autor y cómo ello condiciona su obra? ¿Invirtió el autor las situaciones y las lógicas de las mismas?, etc.

Presento a continuación un breve esbozo de una etapa de la historia de Yugoslavia, desde la segunda guerra mundial a la muerte de Tito, el 
fundador de la república federal, en 1980, como contexto histórico de la obra. Soy consciente del esquematismo de esta reconstrucción, por lo que las relaciones que establezco entre las situaciones externas y algunos elementos significativos de la obra son provisionales.

En 1941, los ustachis crearon con el patrocinio de Hitler y Mussolini el estado independiente de Croacia, que comprendía sólo una parte del territorio habitado por los croatas, pero al que se anexionó Bosnia y Hercegovina, donde eran una minoría. Los ustachis persiguieron a los serbios, a los judíos, a los gitanos y a los croatas antifascistas. Banac (1993: 167) asegura que se exageran los crímenes cometidos por los ustachis y pone como ejemplo el campo de concentración ustachi de Jasenovac, presentado como el tercer campo de exterminio más grande de Europa, con 700.000 serbios asesinados, pero al parecer con un número real de asesinados que oscilaría entre “60.000 y 80.000 , no todos serbios". Bringa (1995: 23) ofrece, por su parte, la siguiente estimación:

Varios cientos de miles de serbios murieron en los campos de concentración ustachi y varias decenas de miles de musulmanes fueron masacrados por serbios nacionalistas.

Kullashi (1999: 270) habla de "cientos de miles de serbios" junto con otras víctimas de los ustachis. Durante el gobierno de Tito hablar de estos hechos se consideraba un acto de chovinismo, contrario al lema de unidad y fraternidad entre los pueblos de la República de Yugoslavia.

En 1946, se constituyó la república popular federal de Yugoslavia, integrada por seis repúblicas y dos regiones autónomas y cuyo lema era "unidad y fraternidad". Bringa (1995: 23) escribe que Tito

decidió que era mejor "olvidar" el pasado y construir una nueva Yugoslavia con un sistema cuidadosamente construido para el equilibrio de poder entre los grupos "étnicos" más grandes, de manera que ningún pueblo dominase a otro.

La identidad de la república federal se forjó en la lucha de liberación contra el fascismo, llevada a cabo por el partido comunista con la participación de miembros de todos los grupos étnicos, y la referencia a las víctimas del fascismo se convirtió en un elemento clave de la retórica política y de la organización de la memoria histórica.

Halpern (1958: 295), que hizo trabajo de campo en una localidad serbia en los años 1953 y 1954, escribe sobre la identificación de la gente con el nuevo sistema político y los estereotipos sobre otros pueblos integrados en él:

Los habitantes de Orasac son conscientes de que formalmente son ciudadanos de Yugoslavia, pero sólo los intelectuales del pueblo dirían que son yugoslavos o su 
lengua el serbo-croata. Es posible que esta actitud cambie gradualmente, ya que la idea de una Yugoslavia unida y ala hermandad de nuestros pueblos" es fuertemente inculcada por la escuela y las organizaciones gubernamentales. Sin embargo, no existe ninguna duda de que en este momento los habitantes del pueblo consideran a los demás eslavos del sur como diferentes. Los macedonios, aunque considerados muy próximos a los serbios, la mayoría de ellos compartiendo la misma religión, son vistos como pobres y atrasados. Una opinión similar se tiene de los bosnios. Los que son musulmanes son llamados "turcos", aunque son eslavos que aceptaron el Islam en la época de la conquista turca.

En 1966, la destitución del responsable de las fuerzas de seguridad de la república federal y la depuración de las mismas fue el punto de partida "de un equilibrio más grande en las relaciones entre las nacionalidades" (Banac 1993: 157) La destitución representó la derrota de los partidarios del centralismo político y económico y el triunfo de los partidarios de la descentralización y democratización de las estructuras económicas y políticas. La interpretación en términos nacionales es que los funcionarios e intelectuales serbios, liderados por el jefe de seguridad, partidarios de la centralización, perdieron peso político. Según Banac (1993: 157), los ganadores afueron los croatas y los musulmanes bosnios y, sobre todo, los albaneses".

Entre los cambios más importantes ocurridos con posterioridad destacan la concesión en 1968 a los musulmanes de Bosnia y Hercegovina del estatus de nacionalidad pero sin territorio propio, la ampliación de la autonomía de Kosovo en 1969, y la nueva constitución yugoslava de 1974 . La concesión del estatus nacional a los musulmanes de Bosnia y Hercegovina pretendía frenar la reivindicación serbia y croata de esta república que según Bowman (1994:151) se basaba en que

los musulmanes eran o bien serbios o bien croatas, que se convirtieron al Islam durante la dominación otomana.

Bringa (1995: 13) escribe sobre los antecedentes de este tema:

Históricamente, desde la retirada de los otomanos del occidente de los Balcanes, Bosnia-Hercegovina se convirtió en el principal escenario para las reclamaciones nacionalistas rivales de serbios y croatas (Bracewell 1993: 154). Estas reclamaciones eran parte de las aspiraciones hegemónicas más amplias de los serbios y croatas sobre Bosnia-Hercegovina: convirtiendo a los musulmanes bosnios en serbios o croatas, en otras palabras, asimilándolos, uno de los dos contendientes se reforzaría considerablemente. La presión sobre la población musulmana para identificarse (o incluso asimilarse) ya sea con la nación croata o la serbia, ha sido, por tanto, fuerte en algunos momentos.

La escritura de la historia sobre Bosnia y Hercegovina desde presupuestos nacionalistas legitimaba las aspiraciones anexionistas. 
La constitución de 1974 (Banac 1993: 158-9), así,

elevaba al rango de repúblicas virtuales las provincias autónomas de Serbia, Kosovo y Voivodina, a la vez que introducía un sistema de paridad absoluta y de proporcionalidad en las relaciones entre las repúblicas y en su participación en los órganos federales.

Esta constitución fue percibida por los serbios como una discriminación contra ellos. La oposición serbia a la constitución de 1974 se incrementó a la muerte de Tito en 1980. Banac escribe (1993:159):

Los líderes serbios tomaron como pretexto las manifestaciones masivas que sacudieron Kosovo y recurrieron a las armas de fuego en marzo-abril de 1981. Sus llamadas a la restricción de la autonomía sólo pueden ser comprendidas como una exageración de la amenaza albanesa y, además, de la de los "autonomistas" de Voivodina.

La expresión del temor de líderes serbios a la "amenaza" albanesa se remontaba como mínimo a las manifestaciones kosovares de 1968.

En 1989, en concurrencia con la procesión de las reliquias de Lazar, se excavaron las fosas del genocidio serbio por los ustachis. Con esta ocasión, el estado serbio y la iglesia ortodoxa celebraron grandes ceremonias político religiosas "en las llanuras en las que están expuestos los huesos desenterrados de las víctimas" (Kullashi 1999: 270). Sells (2001: 185) escribe al respecto:

La acusación de que los croatas y los musulmanes eran pueblos genocidas y tramaban un nuevo genocidio fue repetido por todas las publicaciones de la Iglesia Ortodoxa serbia, se intensificó cuando los militantes desenterraron las víctimas serbias de la segunda guerra mundial, y a ello se le sumó la denuncia inflamada de que los serbios eran ya objeto de genocidio por parte de los albaneses en Kosovo.

Es probable que Draskovitch escribiera esta novela hacia finales de los setenta o comienzos de los ochenta, época en que se publicó (1982). Puede pensarse que los cambios sociales y políticos afectaron al proceso de escritura de la novela, es decir, a la elección de los elementos básicos, pero también que la obra fue un elemento activo en el proceso de afirmación de la identidad serbia y de redefinición de las relaciones interétnicas. El autor usa la imaginación para reivindicar el papel de la memoria histórica como clave para la identidad nacional serbia y, basándose en ella, propugna la integración de los musulmanes. Su modelo de integración es un nacionalismo étnico basado en la continuidad del parentesco y en la reivindicación de un único origen procreativo. Frente al modelo impuesto por el sistema comunista de reforzar ciertas identidades 
étnicas minoritarias o de redefinir a otras para diferenciarlas de las mayoritarias, como mecanismo de contrapeso y equilibrio entre las identidades que formaban la república federal, el autor usa la lógica de la simplificación para destacar y reforzar el protagonismo de una de ellas, la más potente o dominante. Esta lógica de la simplificación, frente a la lógica anterior de la multiplicación, contribuye a legitimar la idea de la gran Serbia, en este caso a través de la localización del inicio de la trama de la novela en Hercegovina y la creación de dos símbolos, las figuras de Sikter y Alija. No se formula la reivindicación explícita del territorio de Hercegovina, pero sí de la identidad serbia no reconocida de los musulmanes de Hercegovina.

Mientras en la novela la idea de Serbia se construye imaginariamente a través de las historias familiares de dos personajes y de referencias a un pasado lejano, en la realidad política la idea de Serbia se construía por oposición frente a los musulmanes de Kosovo, la región autónoma de Serbia. Hercegovina, el escenario de la obra, con presencia de croatas, serbios y musulmanes, era un lugar adecuado para la creación de símbolos para la lógica de simplificación del autor, que se concreta en la integración e, incluso, la asimilación de los musulmanes en la nación serbia. La identidad de los musulmanes basada en la religión es considerada incompleta o insuficiente y, por ello, no debería constituir un obstáculo para la reunificación nacional. Una posición contraria a la de una obra básica del nacionalismo serbio, escrita por el obispo Petar Petrovic II en 1857, en la que se conmina a los musulmanes de Montenegro a convertirse o si no serán exterminados y se rechaza la afirmación de que musulmanes y ortodoxos constituyen un único pueblo.

La elección de la segunda guerra mundial como marco histórico le permite al autor transformar la triple diferenciación étnica en una estructura binaria: croatas y musulmanes contra serbios. Ello es posible adjudicando a croatas y musulmanes la identidad de ustachis. A pesar del gran número de croatas participantes en la resistencia partisana -el ejemplo más sobresaliente fue el mismo Tito-, la estigmatización de la identidad ustachi afectó luego al nacionalismo croata. La unicidad del otro término, a pesar de la confrontación entre chetniks y partisanos, se logra no definiendo políticamente a la familia Jugovic, es decir, no adscribiéndola claramente a ningún bando. Así se resalta su identidad étnica, por encima de la política. Al situar a los croatas y musulmanes como aliados de los invasores, el autor identifica Yugoslavia con los serbios. Por un lado, existen los serbios, los defensores y los que pagaron su lucha con mucho sufrimiento y, por el otro lado, los traidores. No resalta el papel aglutinador del partido comunista que, en su lucha contra el nazismo, unió 
a gentes de todas las etnias y nacionalidades. El autor traduce la oposición ideológico-política de los comunistas entre "Víctimas del fascismo" y "Ocupantes extranjeros y traidores internos" a una oposición en términos étnicos. Más que reivindicar las víctimas del fascismo, reivindica las víctimas serbias.

El libro no se escribe en contra del partido comunista, pero sí desde una perspectiva muy distinta. Se imagina una memoria del pasado desde el punto de vista de la expresión de la identidad étnica y nacional serbia y, por tanto, no mediatizada por los símbolos y el poder del estado federal. La novela, con sus "documentos históricos" - fragmentos de un viejo libro que narra la historia de los serbios en la antigüedad y los documentos que Sikter envía a Alija sobre el genocidio serbio-, parece asumir en parte el estatus de "historia", que enmienda la página a la historia creada y difundida por el régimen comunista. No es una historia, pero parece que haga esta función, de contar una historia reciente, ocultada por el régimen comunista. Se trata de una visión nacionalista del pasado, que destaca el protagonismo y el sufrimiento del pueblo serbio. Esta construcción de la "memoria" hubiera sido considerada antes de la muerte de Tito como instigación del chovinismo y probablemente del revanchismo, pero, después, es un factor más en la redefinición de las identidades. La novela se publica en 1982, pero el capítulo segundo, en que se narra la excavación de una fosa común, se sitúa en 1961. La trayectoria de Alija en los años siguientes le llevará hasta el descubrimiento del genocidio serbio, mucho antes de que los cambios políticos permitieron recuperar y reivindicar públicamente su memoria.

\section{BIBLIOGRAFÍA CITADA}

ANDERSON, BENEDICT. 1993. Comunidades imaginadas. Reflexiones sobre el origen y la difusión del nacionalismo. México: FCE.

BANAC, Ivo. 1993. "L'effrayante asymétrie de la guerre”, en V. Nahoum-Grappe (ed.), Vukovar, Sarajevo... La guerre en ex-Yougoslavie: 149-184. Cahors: Éditions Esprit.

BHABHA, HOMI (ed.). 1990. Nation and Narration. Londres: Routledge.

BOWMAN, GLEN. 1994. "Xenophobia, fantasy and the nation: the logic of ethnic violence in former Yugoslavian, en V. Goddard, J. Llobera y C. Shore (eds.), The Anthropology of Europe. Identity and Boundaries in Conflict: 143-172. Oxford: Berg.

BRINGA, TONE. 1995. Being Muslim the Bosnian Way. Identity and Community in a Central Bosnian Village. Princeton: Princeton University Press.

DRASKOVITCH,VuK. 1993. Le couteau. La Flèche: JC. Lattès (1 $1^{\text {a }}$ edición, 1982).

DURKHEIM, Émile y MARCEL MAUSs. 1996. "Sobre algunas formas primitivas de clasificación", en É. Durkheim, Clasificaciones primitivas (y otros ensayos de antropología positiva): 23-104. Barcelona: Ariel. 
FRIGOLÉ, JOAN. 1995. Un etnólogo en el teatro. Ensayo antropológico sobre Federico García Lorca. Barcelona: Muchnik.

- 1996. "Antígona en Turquía: una convergencia entre antropología y literatura". Revista de Occidente 184: 124-135.

- 1997. "Estructura y simbolismo de Cómo agua para chocolate: jerarquía e incesto", en Manuel de la Fuente y $\mathrm{M}^{\mathrm{a}}$. Ángeles Hermosilla (eds.), Etnoliteratura: una antropologia de ¿lo imaginario?: 47-62. Córdoba: Universidad de Córdoba.

- 2003. Cultura y genocidio. Barcelona: Universitat de Barcelona.

GILSENAN, Michael. 1996. Lords of the Lebanese Marches.Violence and Narative in an Arab Society. Londres: Tauris.

HALPERN, JOEL. 1958. A Serbian Village. Nueva York: Columbia University Press.

HAMmEL, EugEne. 1968. Alternative Social Structures and Ritual Relations in the Balkans. Englewood Cliffs: Prentice-Hall.

Kusllashi, MuHAMEDiN. 1999. "Netoyage ethnique' et génocide en ex Yougoslavie", en C. Coquio (ed.), Parler des champs, penser les génocides: 264-293. París: Albin Michel.

NAHOUM-GrapPe, VÉroniQue. 1993. "L'épuration ethnique: désastre et stupeur", en V. Nahoum-Grappe (ed.), Vukovar, Sarajevo... La guerre en ex-Yougoslavie: 45-79. Cahors: Éditions Esprit.

SELLS, Michafl. 2001. "Kosovo mythology and the Bosnian genocide", en O. Bartov y $\mathrm{Ph}$. Mack (eds.), In God's name. Genocide and Religion in the Twentieth Century: 180-205. Nueva York: Berghahn.

SOMMER, DORIS. 1990. "Irresistible romance: the foundational fictions of Latin America", en H. Bhabha (ed.), Nation and Narration: 71-98. Londres: Routledge. 